\title{
Polimer matrisli elyaf takviyeli kompozit otomobil şasesi vakum infüzyon yöntemi ile imalatı ve mekanik özelliklerinin incelemesi
}

\author{
Manufacture of polymer matrix fiber reinforced composite car chassis by vacuum infusion \\ method and examination of its mechanical properties
}

\author{
Sedat ÜNL ̈̈*1,a \\ ${ }^{1}$ Sakarya Uygulamalı Bilimler Üniversitesi Lisansüstü Eğitim Enstitüsü /Metalurji ve Malzeme Mühendisliği Esentepe/Sakarya

• Geliş tarihi / Received: 03.01.2021 • • Düzeltilerek geliş tarihi / Received in revised form: 01.10.2021 • Kabul tarihi / Accepted: 18.10 .2021

\begin{abstract}
Öz
Teknolojinin gelişimi beraberinde sanayinin temel girdisi olan malzeme biliminde de gelişmelerin hızlanmasını sağlamış, ileri teknolojik malzeme türleri ve bunların üretim yöntemlerini çeşitlendirmiştir. Özellikle havacıllk ve otomotiv sektörlerinde hafif, yüksek mukavemetli ve korozyona dayanımlı ileri teknolojik malzemeler önem taşımakta ve yapısal malzeme olarak kompozit malzemelerin kullanımı artmaktadır. Bu çalışmada; Sakarya Uygulamalı Bilimler Üniversitesi SUBÜ TETRA Elektromobil takımının üretmiş olduğu iki kişilik elektrikli otomobil şasesini karbon fiber ve vinilester epoksi reçine kullanarak vakum infüzyon yöntemi ile imal etmek için farklı parametrelerde numune hazırlanarak mekanik özellikleri incelenmiş ve $1070 \mathrm{~N} / \mathrm{mm}^{2}$ basma mukavemetine sahip numunenin parametreleri kullanılarak şase imalatı yapılmıştır. Dolgu olarak poliüretan 70 dansite köpük kullanılmıştır. Üretim esnasında reçinenin viskozitesi 200-300 cps aralığında tutulmuştur. Vakum ortamı tek kademeli yağlı vakum makinası ile negatif $760 \mathrm{~mm}$ hg basınç altında sağlanmıştır. İmal edilen şase toplam $9.5 \mathrm{~kg}$ ağırlığındadır. Toplamda $140 \mathrm{~kg}$ (şoför hariç) ağırlığa sahip olan araç 300 $\mathrm{km}$ yol almış ve saatte $60-90 \mathrm{~km}$ hızlarda seyir etmiştir. Yapılan yarışlar sonrasında şase üzerinde yapılan tahribatsız muayenelerde batarya bağlantısının düzgün yapılmaması sebebi ile tekrarlı yük altında kalan bölgede görülen şekil değişikliği haricinde şasede deformasyon tespit edilmemiş̧ir.
\end{abstract}

Anahtar kelimeler: İleri teknolojik malzemeler, Karbon fiber, Kompozit, Otomobil, Reçine, Vakum infüzyon, Viskozite, Yüksek mukavemet

\begin{abstract}
Along with the development of technology, it has accelerated developments in materials science, which is the main input of industry, and diversified the types of advanced technological materials and their production methods. Especially in the aerospace and automotive sectors, advanced technological materials with light weight, high strength and corrosion resistance are important and the use of composite materials as structural materials is increasing. In this study Sakarya University of Applied Sciences SUBU produced by the team Elektromobil TETRA two-seater electric car chassis manufactured by vacuum infusion carbon fiber and vinyl ester epoxy resin prepared by using different parameters to the method in the sample were examined and the mechanical properties of $1070 \mathrm{~N} / \mathrm{mm} 2$ to manufacture the chassis by using the parameters of the sample with compressive strength have been made. Polyurethane 70 density foam was used as filling. During production, the viscosity of the resin was kept in the range of 200-300 cps. The vacuum environment is provided under negative $760 \mathrm{~mm}$ hg pressure with a single-stage oil vacuum machine. The manufactured chassis weighs a total of $9.5 \mathrm{~kg}$. A total weight of $140 \mathrm{~kg}$ (excluding the driver), the vehicle traveled $300 \mathrm{~km}$ and traveled at speeds of 60$90 \mathrm{~km}$ per hour. During non-destructive inspections of the chassis after the races, no deformation of the chassis was detected, except for the change in shape observed in the area under repeated load due to the fact that the battery connection was not made properly.
\end{abstract}

Keywords: Advanced technological materials, Carbon fiber, Composite, Automobile, Resin, Vacuum infusion, Viscosity, High strength

\footnotetext{
${ }^{* a}$ Sedat ÜNLÜ; unlusedat54@ gmail.com; Tel: (0544) 64354 29; orcid.org//0000-0003-1510-629X
} 


\section{Giriş \\ 1. Introduction}

Ulaşım araçların da ağırlık azalması daha az yakıt veya enerji tüketimi ve bunun sonucu olarak içten yanmalı motorlarda daha düşük egzoz emisyonlarına elektrikli araçlarda ise menzil artışına yol açtığı için hafif yapıya sahip araç tasarımları ve buna bağlı olarak malzeme seçimleri olduğu görünüyor (Şekil 1).

Elektrikli araçların menzili henüz tatmin edici değildir. Enerji depolama sınırlamasından dolayı elektrikli araç sık sı1k şarj etmeye yol açar. Aracın ağırlığı aracın menzilini sinırlayan anahtar etkenlerden biri olduğu için aracın ağırlık azalması elektrikli araçlarda batarya kapasitesini arttırmak için potansiyel konulardan biridir (Ölmez, 2018). Hafif malzemeler kullanılarak aracın ağırlığını azaltma daha iyi performans sağlar ve aynı zamanda daha uzun mesafeler seyahate olanak sağlar. Herhangi bir araç için hafif malzemeler kullanılırken, onlar elektrikli araçlar için özellikle önemlidir (Carpenter, 2008). Yukarıdaki nedenlerden dolayı, birçok girişim otomotiv parçalarının ağır metal malzemeler yerine hafif malzemeler ile yer değiştirmeye başlamıştır. Hafif malzemeleri magnezyum, alüminyum, gelişmiş yüksek dayanımlı çelikler, titanyum ve de cam ve karbon fiberle takviye edilmiş polimer matrisli kompozitleri içerir (Öz, 2014).

Kompozit malzemeler genellikle matris ve takviye denilen iki farklı fazdan oluşmaktadır. Matrix fazı malzemenin genel hacmini oluştururken takviye olarak kullanılan faz ise malzemenin üzerindeki gerilimi alır. $\mathrm{Bu}$ iki bileşenden takviye elemanı olarak kullanilan ürün kompozit malzemenin tokluğunu, mukavemet ve darbelere karş1 dayanımını artırmak gibi mekanik özellikleri iyileştirirken diğer bileşen olan matris elemanı ise deformasyona geçişte oluşabilecek çatlak oluşumunu ve ilerlemelerini önleyici görev üstlenmekte ve kompozit malzemenin kopmasını veya kırılmasının önüne geçmektedir. İçerisine karıştığ1 kompozit malzemenin çoğunluğunu oluşturan matris bir görevi de takviye elemanı olarak kullanılan malzemeleri yük altında bir arada tutabilmek ve uygulanan yükü homojen bir şekilde parçanın tamamına dağıtmaktır. Kompozit malzemelerde birleşimi meydana çıkartan yapılar tepkime sırasında çözünmezler, kimyasal olarak inert davranış sergilerler.

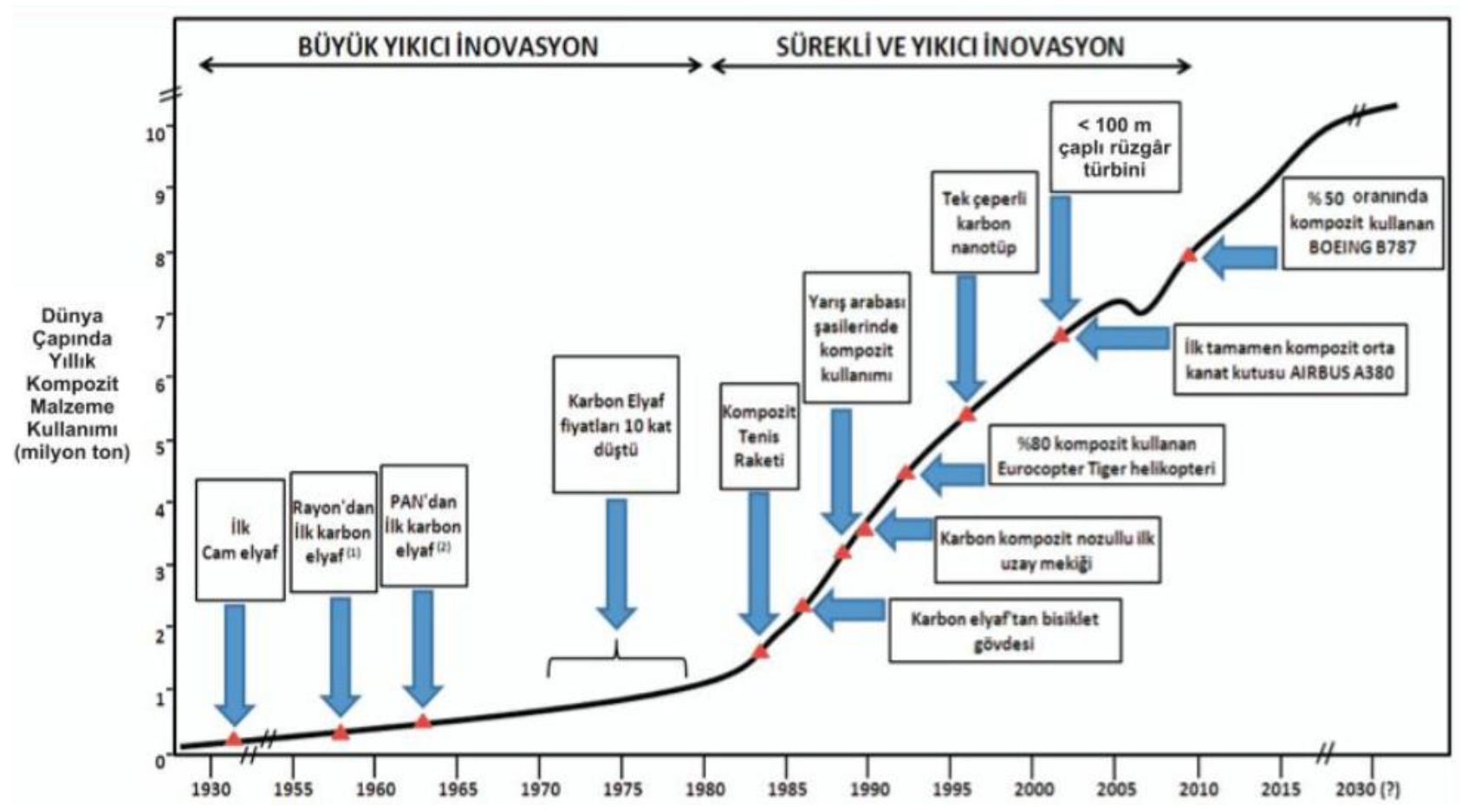

Şekil 1. Kompozit sektörünün yıllara göre gelişimi

Figure 1. The development of the composite sector over the years

Balıkoğlu vd., (2016) yılında yaptığı çalışmada elyaf olarak $300 \mathrm{gr} / \mathrm{mm}^{2}$ cam elyaf, matris fazı olarak vinilester reçine kullanarak sandviç kompozitlerin mekanik davranışları üzerine araştırma yapmışlardır. Dolgu malzemesine açılan farklı çap ve mesafe değerlerinin, eğilme ve basma 
davranışlarına etkisini araştırmıştır. Eğilme yükü altında, delik içeren numunelerde, reçine dolan delikler çivi gibi davranarak tabakaları dolgu malzemesine bağlamış ve dayanım değerlerinin yükselmesini sağlamıştır. Reçine olukları içeren kompozit parça, takviyeli malzeme gibi davranarak rijitliğin artmasına neden olduğunu tespit etmiştir. PVC kor içeren sandviç kompozitlerin yük taşıma kapasitesi \%34 kesik-oluklu PVC içeren sandviç kompozitler de ise $\% 100$ üzerinde yük taşıma kabiliyetleri artmıştır (Balıkoğlu vd., 2016). Elektrikli Araç Uygulamaları İçin Hafif Kompozit Şase Tasarımı ve Geliştirilmesi adlı çalışmada tek yönlü $300 \mathrm{~g} / \mathrm{m}^{2}$ karbon fiber kumaş ve epoksi, polimer matrisli kompozit malzeme üretmek için kullanmıştır. Vakum infüzyon tekniği ile numunelerini üretmişlerdir. Maksimum yer değiştirme sürücü ve yolcu kabinin zemininde gözlemlemişlerdir (Özarslan vd., 2018).

Fan vd., (2007) kıvrımlı dokuma sandviç paneller imal ederek üzerinde çalışmalar yapmışlardır. 200 $\mathrm{gr} / \mathrm{mm}^{2}$ karbon fiberi 3 boyutlu dokuma metodu yüzey-göbek ayrılma direncini arttırdığını ve mekanik testler yapılarak hasar modları ve hasar davranışları belirlemişlerdir. İzotropik olmayan bir yapıya sahip olarak imal edilen paneller farklı yönlerde üç nokta eğme testleri ile basma testleri yapılmıştır. Test sonuçlarına bakıldığında üç nokta eğme testlerinde yüzey-göbek ayrılması gözlemlenmemiştir. Göbek yapı sinüs dalgasına benzer yapıya sahip olduğundan basma testinde yapışma yüzeyleri arası kayma dayanımının düşük çıktığ gözlemlenmiştir. Fan ve arkadaşları trapez geometrisindeki göbek yapısının kayma dayanımının daha yüksek çıkacağını ön görmüşlerdir (Fan vd., 2007).

\section{Vakum infüzyon yöntemi ile parça üretimi}

\section{Production of parts by vacuum infusion method}

Deneysel çalışmalar için hazırlanan numuneler ve nihai ürün imalatı için vakum infüzyon yöntemi tercih edildi. Elyaf olarak CX400 $45^{\circ}-45^{\circ}$ biaxial twil karbon fiber, matris malzemesi olarak Polives 702 vinilester reçine, dolgu malzemesine ihtiyaç duyulan numunelerde ve nihai üründe AIREX 70 dansite (yeşil köpük) kullanıldı (Şekil 2/2). Üretim sürecinin ilk aşaması olan laminasyon planı olarak kalıp, karbon fiber, gerekli ise dolgu malzemesi, karbon fiber, soyma kumaşı, akış filesi ve vakum naylonu olarak belirlendi (Şekil 2/3). Üretilecek numune ölçüleri belirlendikten sonra elyaf malzemesi kesildi ve katı/sıv1 kalıp ayıracı uygulanmış ve kurumuş kalıp yüzeyine birimci ve ikinci yüzey dokuları çapraz olacak şekilde elyaf dikişleri bozulmadan yerleştirildi. Dolgu malzemesi üzerine reçine olukları diye adlandırılan reçine akışına yol verecek ve dolgu malzemesine reçinenin işlemesi için ilgili kanallar açıldı. Bu işlemi tamamlanan dolgu parçası elyaf malzemesi üzerine konuldu ve üzerine altta yer alan elyafa çapraz olacak şekilde karbon fiber yerleştirildi. Numune ölçülerinde kesilen soyma kumaşı numune üzerine yerleştirildi ve reçine akış yönüne paralel reçine akış filesi kullanıldı. İlgili laminasyon planında yer alan bu işlem adımları tamamlandıktan sonra kalıp etrafina vakum işlemi için spiral hortum döşendi (Tablo 1). Spiral hortumun dışına sızdırmazlık sağlaması amacı ile çift taraflı vakum bantı yapıştırıldı (Şekil 2/4). Bunun üzerine ise vakum torbası yapıştırıldı. $\mathrm{Bu}$ işlem sırasında vakum naylonu bol birakılarak basınç altındayken fazla gerilme kaynaklı kaçak oluşumunun önüne geçilmesi amaçlandı. Vakum çıkışı yapılan bölgenin ters simetriğinde reçine girişi için reçine giriş rekoru koyuldu ve vakum torbas1 kapatıldı. Vakum işlemi sırasında pompanın negatif $760 \mathrm{~mm}$ hg basınç oluşturulması sağlandı. Kaçak kontrolü vakum pompası üzerinde yazan değer ve işitme yolu ile kontrol edildi var olan kaçaklar giderildikten sonra reçine girişi numune parçaya yapıldı (Şekil 2/5). Vakum hattında reçine yürümesi olana kadar parçanın tamamının 1slanması beklendi. Parça \%100 1slandıktan sonra reçine giriş hattı kapatıldı ve sonra vakum hattı kapatıldı. Tekrar kaçak kontrolü yapılarak basıncın devam etmesi sağlandı. Parça üzerinden kürleşme reaksiyonu sicaklık yolu ile takıp edildi ve bu şekilde yirmi dört saat bu şekilde oda sıcaklığında parçanın kürleşmesi beklendikten sonra numune parça kalıptan çıkarıldı. Vakum infüzyon yöntemi ile imalat sürecinde en önemli parametrelerden birisi reçinenin viskozitesidir. $\mathrm{Bu}$ sebep ile bu çalışmada Polives 702 (viskosite: 220 cp) kullanıldı. Vakum işlemine başlamadan önce farklı oranlarda karışım yapılarak reçine kürleşme süresine bakıldı ve reçine karışım oranları reçine ağırlı̆̆ının \%o 5-8 hızlandırıcı \%3-5 sertleştirici olarak belirlendi. Numune çalışmalarında viskozite ölçümü yapılmayıp viskozite kontrol altında tutulmasa da şase imalatı sırasında ortam sıcaklığı oda sicaklığında sabitlenmiş ve reçine viskozitesi 200-300 cps aralığında olduğu kontrol edilerek bu aralıkta olması sağlandı. 


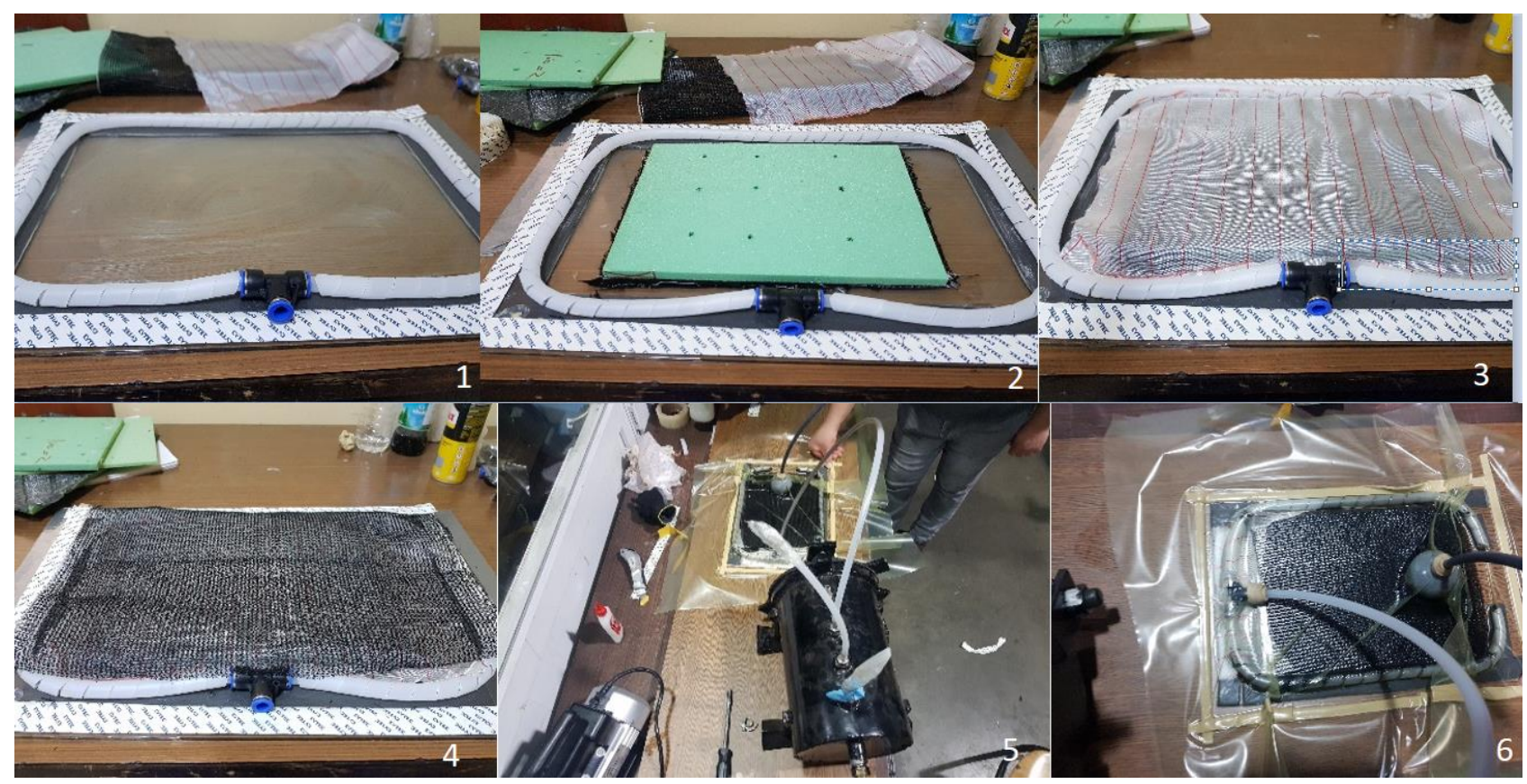

Şekil 2. Vakum infüzyon yöntemi ile numune üretim aşamaları (1: Kalıp ayıracı uygulanmış yüzey 2: Alt tabaka ve dolgu malzemesi uygulanış1 3: Üst tabaka ve ayırma kumaşı uygulanış1 4: Akış filesi uygulanış1 5: Vakum sisteminin kurulması 6: Vakum altında parçanın 1slatılması)

Figure 2. Stages of sample production by vacuum infusion method (1: Mold seperator applied surface 2: Bottom layer and filler application 3: Top layer and application of seperator fabric 4: Application of flow mesh 5: Installation of vacuum system 6: Piece wetting under vacuum)

Tablo 1. 3 nokta eğme testi için hazırlanan numune özellikleri

Table 1. Characteristics of the sample prepared for the 3-point bending test

\begin{tabular}{|c|c|c|c|}
\hline Numune No & Dolgu Malzemesi (mm) & Takviye Elemanı (mm) & Matris Elemanı \\
\hline 1 & 270x190x10 köpük & $\begin{array}{c}\text { 270x190x1 Ölçülerinde } 4 \\
\text { adet karbon fiber }\end{array}$ & $\begin{array}{c}450 \text { gr Vinlister epoksi } \\
\text { reçine }\end{array}$ \\
\hline 2 & 270x190x(10+5) köpük & $\begin{array}{c}\text { 270x190x1 Ölçülerinde } 4 \\
\text { adet karbon fiber }\end{array}$ & $\begin{array}{c}550 \text { gr Vinlister epoksi } \\
\text { reçine }\end{array}$ \\
\hline 3 & 270x190x(5+5) köpük & $\begin{array}{c}\text { 270x190x1 Ölçülerinde } 4 \\
\text { adet karbon fiber }\end{array}$ & $\begin{array}{c}550 \text { gr Vinlister epoksi } \\
\text { reçine }\end{array}$ \\
\hline 4 & 270x190x5 köpük & $\begin{array}{c}\text { 270x190x1 Ölçülerinde } 4 \\
\text { adet karbon fiber }\end{array}$ & $\begin{array}{c}425 \text { gr Vinlister epoksi } \\
\text { reçine }\end{array}$ \\
\hline
\end{tabular}

\section{Sonlu elemanlar analiz ve modelleme}

3. Finite element analysis and modeling

Şase ve araç tasarımı SolidWorks ve Catia V5 tasarım programları kullanılarak Tübitak Yarış kurallarına uygun olarak 3 boyutlu tasarlandı (Şekil 3 ve 6). Hava akış analizleri, burulma ve eğilme analizleri ve termal analizler Flow Design, ANSYS ve SolidWorks programları kullanılarak yapıldı (Şekil 4 ve 5). 

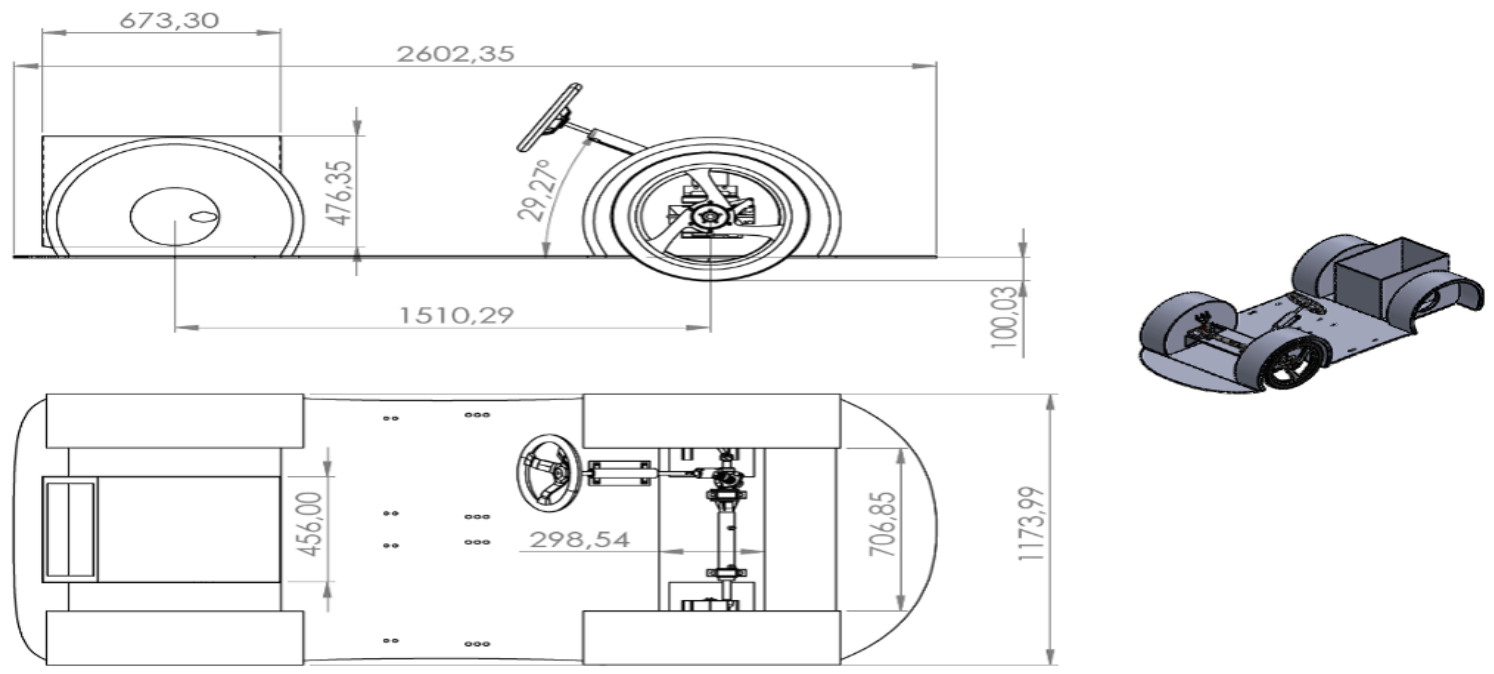

Şekil 3. Şase tasarımı ve teknik ölçüler

Figure 3. Chassis design and technical dimensions

Model adı:1. numune

Etüt adı:Static 1(-Varsaylan-)

Grafik tipi: Statik gerinim Gerinim1

Deformasyon ölçeği: 0.627717
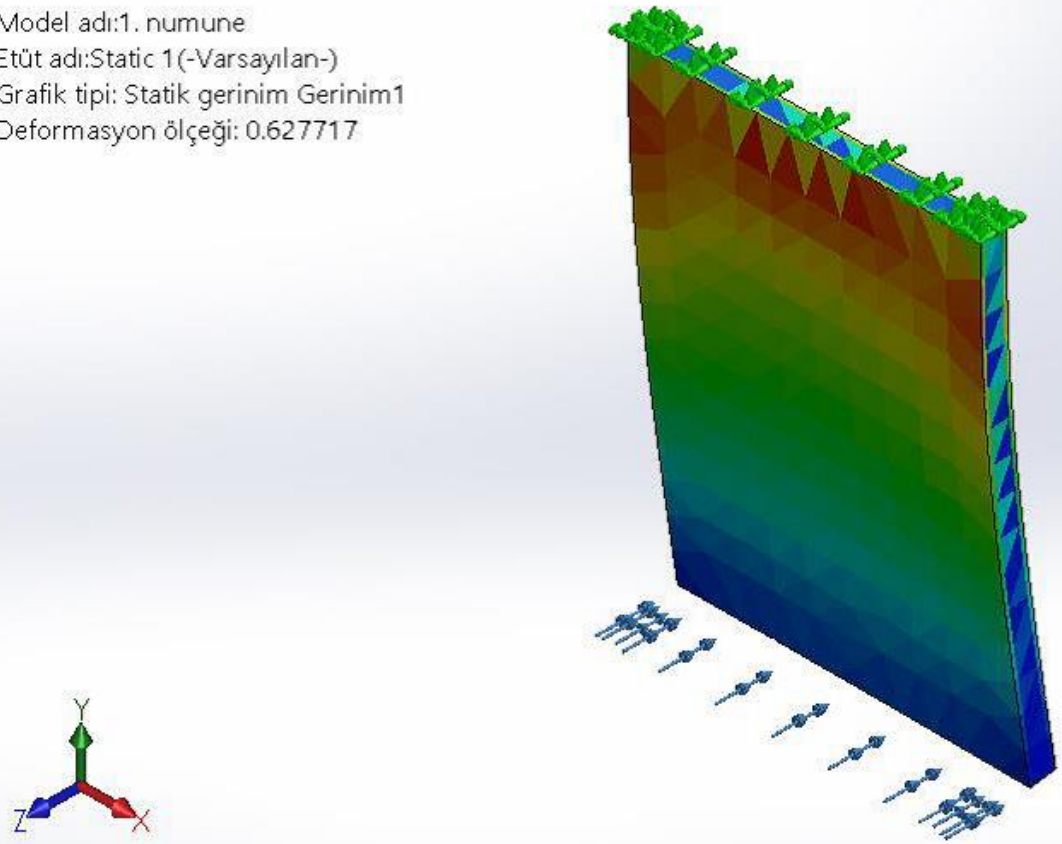

ESTRN

$1.119 \mathrm{e}-02$

$1.027 e-02$

$9.340 e-03$

$8.415 e-03$

$7.489 e-03$

$6.564 \mathrm{e}-03$

$5.638 \mathrm{e}-03$

$4.713 e-03$

$3.787 e-03$

$2.862 \mathrm{e}-03$

$1.936 \mathrm{e}-03$

$1.011 \mathrm{e}-03$

$8.539 e-05$

Şekil 4. Etüt Sonuçları (Tek kat karbon fiber 70 dansite dolgu)

Figure 4. Survey Results (Single layer carbon fiber 70 density filler) 
Model ad: 4. numune

Etüt adl:Static 2(-Varsayllan-)

Grafik tipi: Static dǚ̈um stresi Stres

Deformasyon ölçeği: 1
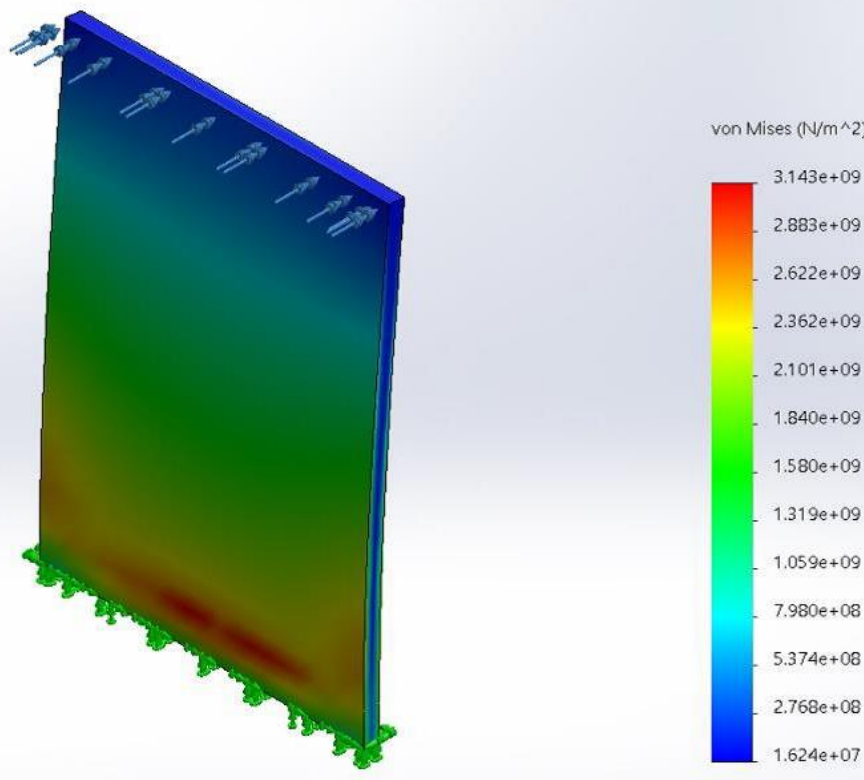

Şekil 5. Etüt sonuçları (2 kat karbon fiber 70 dansite dolgu)

Figure 5. Survey results (2 layers of carbon fiber 70 density filler)

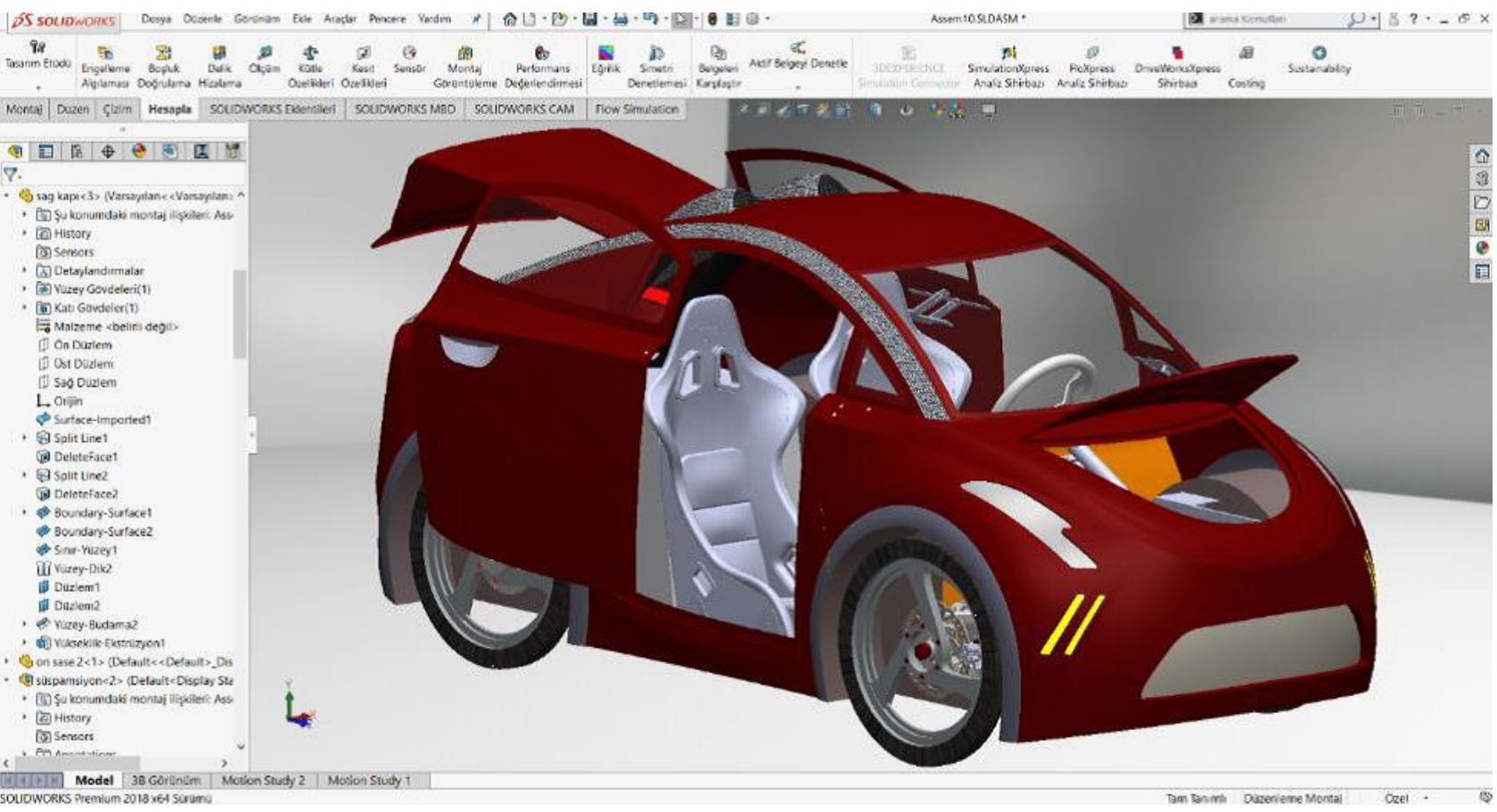

Şekil 6. Etüt sonuçları (2 kat karbon fiber 70 dansite dolgu)

Figure 6. Composite chassis applied in vehicle design

\section{Bulgular ve tartışma}

\section{Results and discussion}

Mekanik testler için imal edilen numuneler belirlenen standartta (ASTM C393/C393M-11) uygun olarak üç nokta eğme testine tabi tutuldu.
İlgili test için mesnetler arası mesafe $200 \mathrm{~mm}$ olarak belirlendi. (SSekil 7) İlgili test İNSTRON hidrolik çekme-basma cihazında $6 \mathrm{~mm} / \mathrm{dak}$ yükleme hızıyla gerçekleştirildi. Deplasman değerleri potansiyometrik cetvel ile numune alt, orta noktasından alınmıştır. 


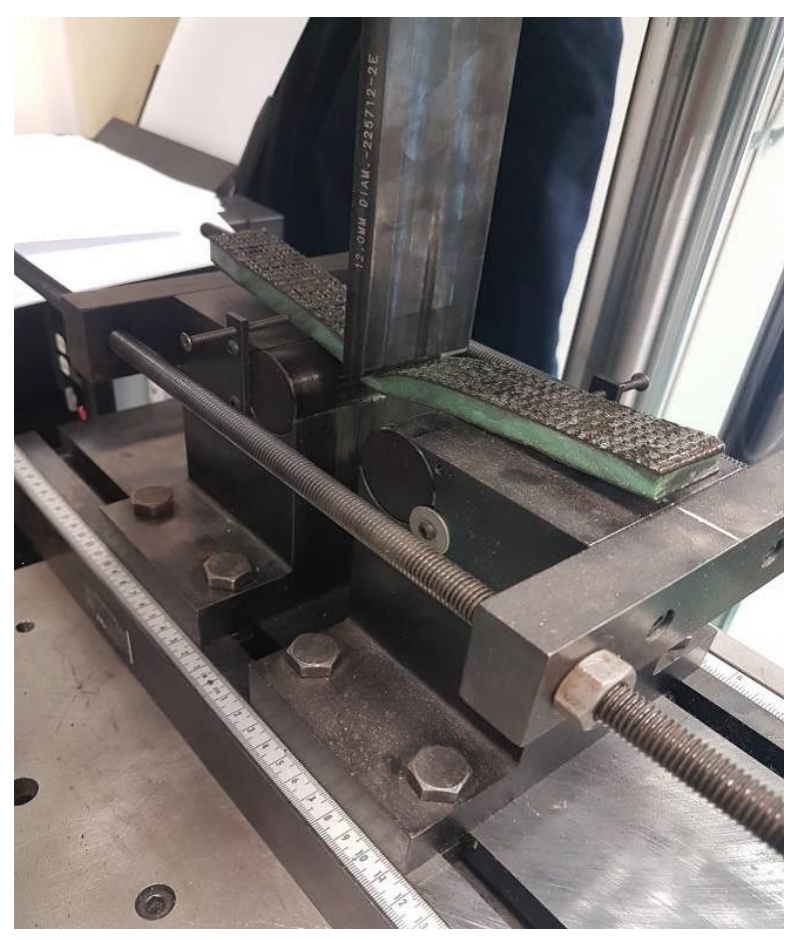

Şekil 7. Eğme testi uygulaması

Figure 7. Application of bending test

1 numaralı numunenin testleri İNSTRON 300DX markalı eğme ve basma cihazında yapıldıktan sonra çıktıları alınıp raporlandı. Sonrasında ise deney sonuçları (Tablo 2) Excel programında grafik haline getirildi. (Şekil 8) Grafikteki dalgalanma dolgu malzemesine reçinenin tam anlamıyla nüfuz etmediği ve malzemenin sünek davrandığının göstergesi olarak düşünülmektedir.

Tablo 2. 1. Numune test sonuçları

Table 2. Test results of $1^{\text {st }}$ sample

\begin{tabular}{lllll}
\hline Uzama (mm) & E5 Yük $(\mathbf{N})$ & E6 Yük $(\mathbf{N})$ & E7 Yük $(\mathbf{N})$ & Ortalama yük \\
\hline 0 & 0 & 0 & 0 & 0 \\
2.5 & 400 & 50 & 0 & 150 \\
5 & 630 & 310 & 0 & 313.33 \\
7.5 & 600 & 520 & 290 & 470 \\
10 & 545 & 530 & 630 & 568.33 \\
12.5 & 490 & 440 & 560 & 496.66 \\
15 & 500 & 420 & 500 & 473.33 \\
17.5 & 510 & 400 & 360 & 423.33 \\
20 & 500 & 410 & 380 & 430 \\
22.5 & 540 & 510 & 360 & 470 \\
25 & 500 & 600 & 390 & 530 \\
27.5 & 530 & 640 & 430 & 533.33 \\
30 & 560 & 560 & 470 & 530 \\
32.5 & 510 & 590 & 590 & 563.33 \\
35 & 520 & 570 & 730 & 606.66 \\
37.5 & 510 & 500 & 810 & 606.66 \\
40 & 500 & & 840 & 670 \\
42.5 & 640 & & 910 & 775 \\
\hline
\end{tabular}




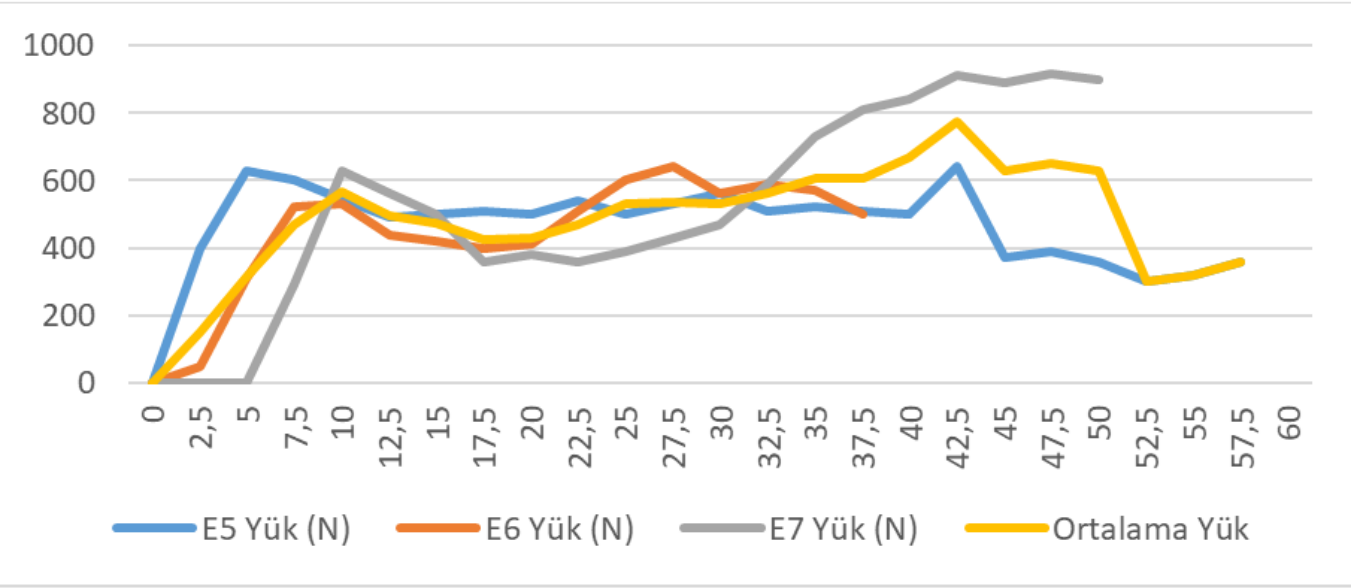

Şekil 8. Birinci numune verileri

Figure 8. First sample data

1. Numunenin test sonuçları kullanılarak maksimum eğilme miktarı $12400 \mathrm{Nmm}$, şekil değiştirme miktarı 0.7470, eğilme mukavemeti $73.136 \mathrm{~N} / \mathrm{mm}^{2}$ ortalama kuvvet $775 \mathrm{~N}$ olarak aşağıdaki denklemlerde hesaplanmıştır

Max. Eğilme Miktarı

F.L $/ 4=775.64 / 4=12400 \mathrm{Nmm}$

Şekil Değiştirme Miktarı

6.y.d $/ /^{2}=6 \times 42.5 \times 12 / 64^{2}=0.7470$

Eğilme Mukavemeti $\sigma_{\mathrm{e}}=12400 / 3.14 .12^{3} / 32=73.136 \mathrm{~N} / \mathrm{mm}^{2}$

Elastik Modülü $\varepsilon=\sigma_{\mathrm{e} / \mathrm{e}}=73.136 / 0.7470=97.90 \mathrm{~N} / \mathrm{mm}^{2}$

\begin{abstract}
Ortalama $\mathrm{F}=775 \mathrm{~N}$
ASTM C393 L=64mm y=42.5

Eğilme $\mathrm{H}_{1 \mathrm{zl}}=10 \mathrm{dk} / \mathrm{mm}$

Mandren çap $1=12 \mathrm{~mm}$

2 ve 3 numaralı numunede çift katman köpük kullanıldığı ve köpüklere açılan reçine akış delik merkezleri denk gelmediği için tabakalar arası reçine nüfüziyeti olmamış dolayısıyla sünek ve sert olmayan bir sonuç elde edildi. $\mathrm{Bu}$ yüzden numuneler teste tabi tutulmadi. Şekil 9 'da 3 numaralı numuneden kesilen bir parçadan iç kısım görseline yer verilmiştir. Reçinenin açılan reçine oluğu dışında iki parça arasına işlemediği tespit edilmiştir.
\end{abstract}

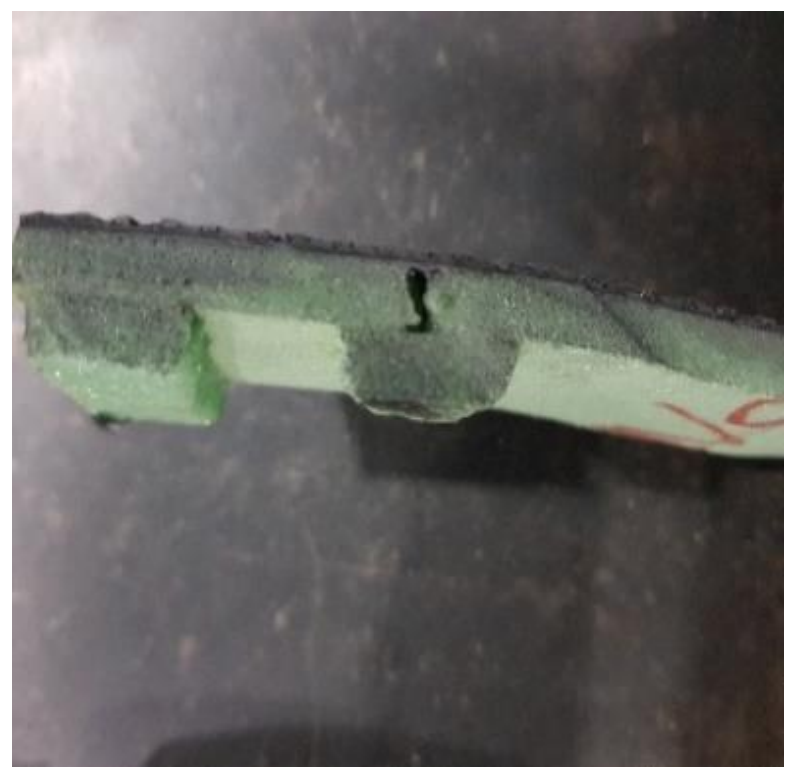

Şekil 9. Üç numaralı numune iki dolgu tabakası birleşim görüntüsü

Figure 9. Sample number three is a combination image of two filler layers 
4 numaralı numenin sonuçları alınıp Excel programında alınan test sonuçları düzenlenip grafik haline getirildikten sonra asıl istenilen sonuçlara ulaşılmıştır.4 numaralı numunenin eğme deneyi test sonuçları Tablo 3 'te gösterilmektedir. Şekil 10 'da verilen 4. Numuneye ait grafikte dalgalanma olmaması malzemenin sünek olmadığı ve dolgu malzemesine reçinenin nüfuz ettiği düşünülmektedir. Test sonrası yapılan görsel muayenede matris malzemesinin dolgu malzemesine işlediği ve istenilen sonuca 4 numaralı parçada ulaşıldığı tespit edilmiştir.

Tablo 3. 4. Numune test sonuçları

Table 3. Test results of $4^{\text {th }}$ sample

\begin{tabular}{lllll}
\hline Uzama $(\mathbf{m m})$ & E8 Yük (N) & E9 Yük (N) & E10 Yük (N) & Ortalama Yük (N) \\
\hline 0 & 0 & 0 & 0 & 0 \\
1 & 110 & 200 & 200 & 170 \\
2 & 315 & 420 & 410 & 381.66 \\
3 & 530 & 610 & 610 & 583.33 \\
4 & 800 & 820 & 820 & 813.33 \\
5 & 1010 & 1000 & 910 & 973.33 \\
6 & 1130 & 1100 & 760 & 996.66 \\
7 & 1210 & 1060 & 620 & 963.33 \\
8 & 1070 & & & 1070 \\
9 & 890 & & & 890 \\
\hline
\end{tabular}

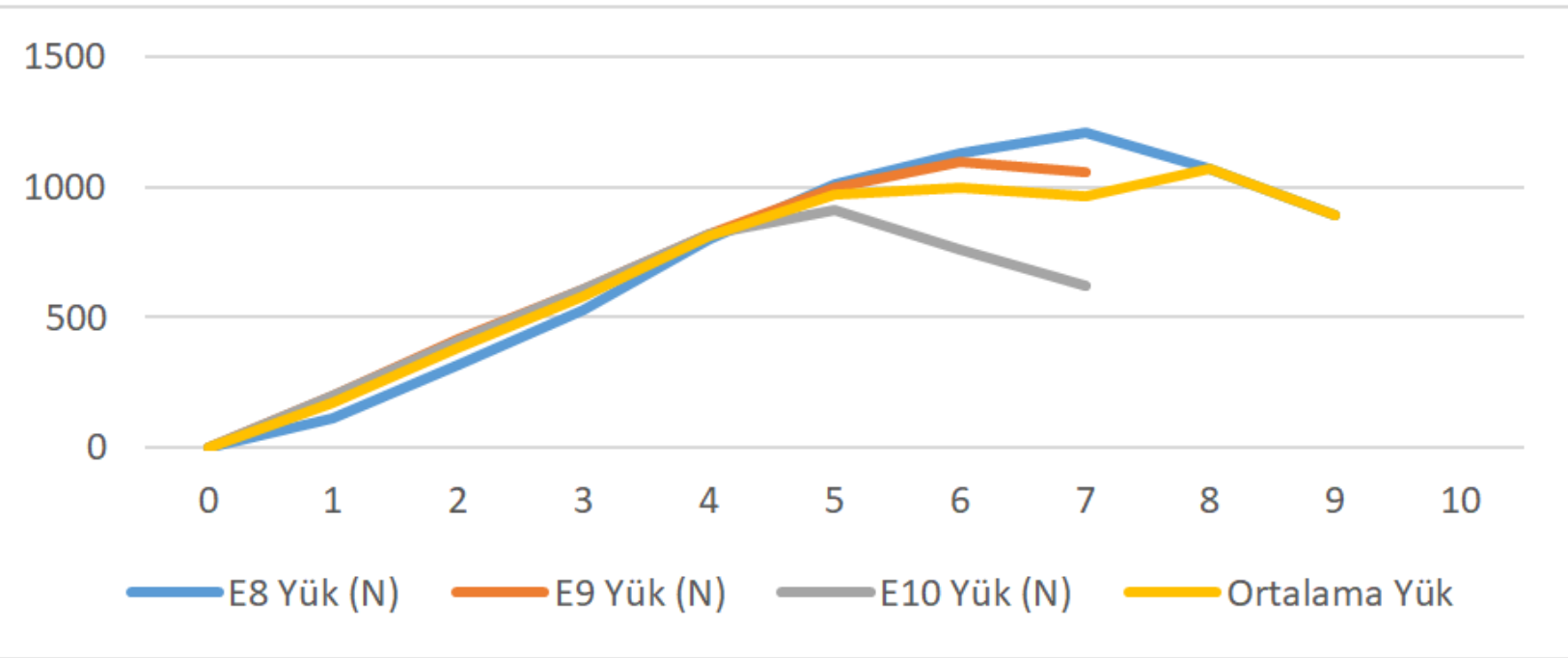

Şekil 10. Dördüncü numune test sonuçları

Figure 10. Fourth sample test results

4. numune test sonuçları kullanılarak maksimum eğilme miktarı $24075 \mathrm{Nmm}$ şekil değiştirme miktarı 0.071 eğilme mukavemeti $142.985 \mathrm{~N} / \mathrm{mm}^{2}$ elastik modülü $1999.778 \mathrm{~N} / \mathrm{mm}^{2}$ ortalama kuvvet $1070 \mathrm{~N}$ olarak aşağıdaki denklerde hesaplanmıştır.

Max. Eğilme Miktarı

F.L $/ 4=1070 \times 90 / 4=24075 \mathrm{Nmm}$

Şekil Değiştirme Miktarı

6.y.d $/ /^{2}=6 \times 8 \times 12 / 90^{2}=0.071$

Eğilme Mukavemeti

$\sigma_{\mathrm{e}}=24075 / 3.14 .12^{3} / 32=142.985 \mathrm{~N} / \mathrm{mm}^{2}$
Elastik Modülü

$\varepsilon=\sigma_{\mathrm{e} / \mathrm{e}}=142.985 / 0.072=1999.778 \mathrm{~N} / \mathrm{mm}^{2}$

Ortalama $\mathrm{F}=1070 \mathrm{~N}$

ASTM C $393 \mathrm{~L}=90 \mathrm{~mm}$ y $=8$

Eğilme $\mathrm{Hızı}=6 \mathrm{dk} / \mathrm{mm}$

Mandren çap $1=12 \mathrm{~mm}$

Şase üretimi öncesi üretilip ve mekanik özelliklerini incelenen 4 farklı numunenin her birinin içi kesilerek iç yapısı incelenmiş ve görüntü alınmıştır. 1. ve 4. numunelerde dolgu malzemesine açılan delik çevresinde bir (1) $\mathrm{cm}$ çapında reçine nüfüziyeti gözlemlenmiştir. Karbon ile dolgu malzemesi arasında yüzeysel bir yapışma, 
dolgu malzemesine açılan delik dışında reçineyi yüzeysel emdiği fark edilmiştir (Şekil 11/b). Çift katlı dolgu malzemesi kullanılan numunelerinde (2. ve 3. numune) iki dolgu malzemesi arasinda açılan delik dışında hiçbir yerde yapışma gözlemlenmemiştir (Şekil 11/a).

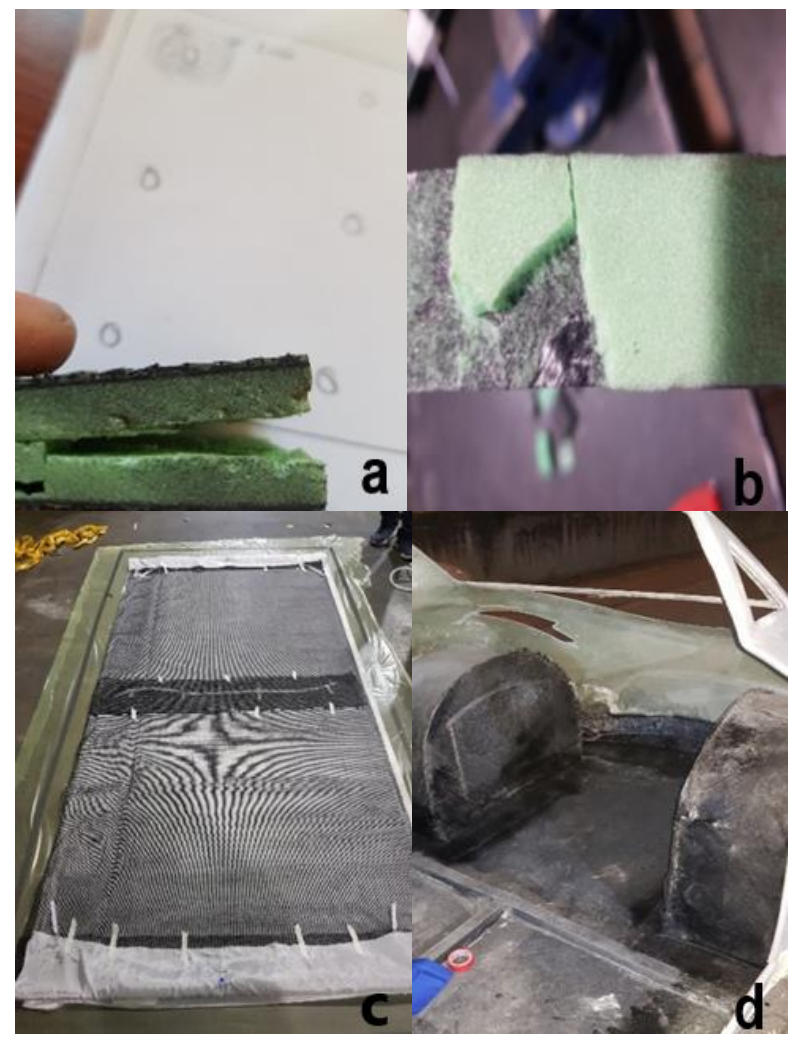

Şekil 11. Kesilen numunelerden içyapı görüntüleri ve (a-b) şase imalat aşamaları (c-d)

Figure 11. Internal structure images from the cut samples and ( $a-b)$ chassis manufacturing stages (cd)

Fatih ve arkadaşlarının 2015 yılında yaptığı çalışmada edinilen sonuca paralel bir sonuç bu çalışmada da elde edilmiştir. Reçine akışı için açılan akış olukları tekrarlı yükler altında kırılmalara sebebiyet verdiği imal edilen şase üzerinde gözlemlenmiştir. Fan ve arkadaşlarının yaptığ yapışkanlığı problemini vakum infüzyon sırasında oluşan kaçakları ve vakum ortamını stabil basınç altında tutarak bu çalışmada aşılmıştır.

4. numune parametreleri baz alınarak $9.5 \mathrm{~kg}$ ağırlığında şase imalatı tamamlanmış olup kabuk ile monokok bir şekilde epoksi yapıştırıcı ve perçinleme yöntemi ile bağlantısı yapılmıştır. (Şekil 11) $140 \mathrm{~kg}$ toplam ağırlığa ulaşan araç Tübitak Efficiency Challenge 2019 yarışlarında 60 $\mathrm{km}$ yol alarak bir önceki yarışa göre enerji tüketimini $70 \mathrm{kWh}$ azaltarak $58 \mathrm{kWh}$ ile Türkiye 7.si olmuştur. 2020 yarışlarında ise bu enerji tüketimini kompozit jant ilavesi ile $49 \mathrm{kWh}$ 'a düşürmüş ve Türkiye 3.sü olmuştur.

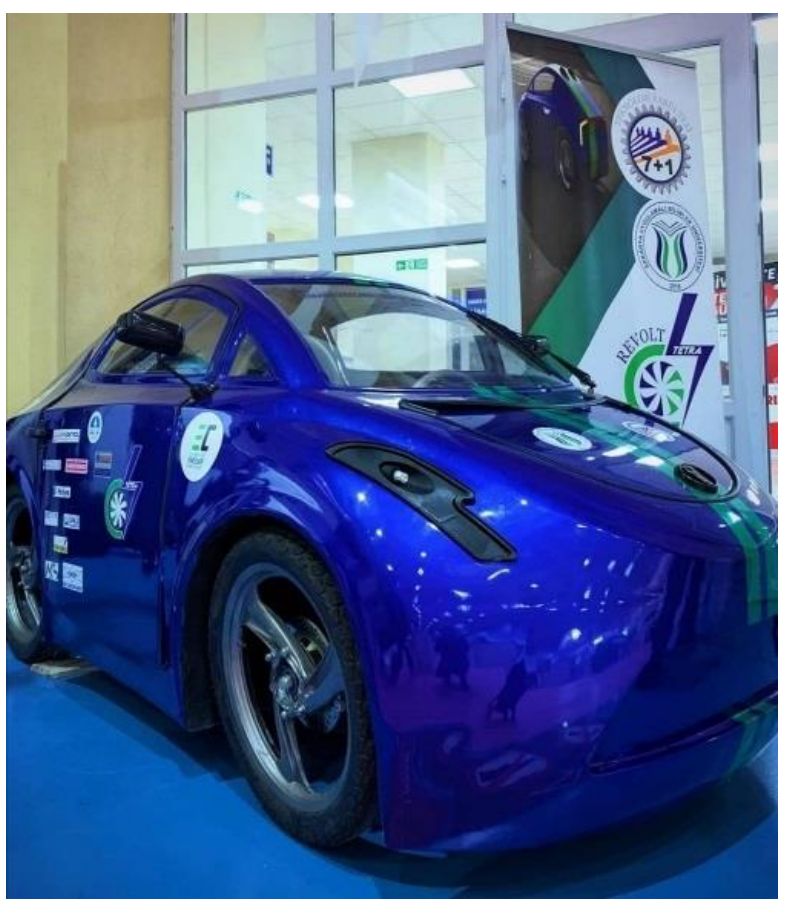

Şekil 12. Kompozit şaseye sahip iki kişilik REVOLT

Figure 12. Two-seater RE-VOLT with composite chassis

\section{Sonuç ve öneriler \\ 5. Conclusion and suggestions}

$\mathrm{Bu}$ çalışmada Sakarya Uygulamalı Bilimler Üniversitesi elektromobil takımının Tübitak Alternatif Enerjili Araçlar 2019 yarışları için tasarladığı RE-VOLT adlı aracın (Şekil 12) kompozit şase imalatı karakterizasyonu için çeşitli numuneler alınmıştır.

İmalat yöntemi olarak seçilen vakum infüzyon yöntemi numune imalatında elde edilen mekanik değerler, homojen matris dağılımı ve dolgu malzemesi ile elyaf ara yüzey yapışma direnci göz önünde bulundurularak doğru seçim olduğu sonucuna varılmıştır. Vakum ortamı oluşturmak için yapılan torbalama yönteminde yaşanan kaçakların önüne vakum bantı değişimi ile geçilmiştir.

Dolgu malzemesinde reçine akışını sağlamak için açılan reçine kanalları tekrarlı yükler altında kırılmaya sebebiyet verdiği aracın yol testlerinde tespit edilmiş olup reçine akışı için açılan kanallar yerine reçine olukları kullanılabilir.

2018-2019-2020 yıllarında yapılan yarışmalarda Al şase ve kompozit şase, aynı sürtünme 
katsayısına sahip ve aynı tasarım ile imal edilen araçlarda Al şase kullanıldığında (toplam araç ağırlığ $240 \mathrm{~kg}$ ) $1 \mathrm{~km}$ 'de ortalama $55 \mathrm{Wh}$ enerji tüketimine sahipken bu değer kompozit şase ile (toplam araç ağırlığı $155 \mathrm{~kg}$ ) $30 \mathrm{Wh}$ değerlerinde ölçülmüştür. $\mathrm{Bu}$ verilerden yararlanılarak araç ağırlığı ile enerji tüketiminin doğru orantılı olduğu ve kompozit malzemelerin otomobil teknolojisindeki yeri ve önemini açıklamaktadır.

\section{Yazar katkısı \\ Author contribution}

$\mathrm{Bu}$ çalışmanın bilgisayar ortamında modellenmesi ve analiz çalışmaları, literatür araştırması, numune ve şase imalatı mekanik testleri tarafımca yapılmış ve bu adımları barındıran her süreçte görev alınmıştır.

\section{Etik beyanı}

Declaration of ethical code

Bu çalışmada, Yükseköğretim Kurumları Bilimsel Araştırma ve Yayın Etiği Yönergesi” kapsamında uyulması gerekli tüm kurallara uyulduğunu, bahsi geçen yönergenin "Bilimsel Araştırma ve Yayın Etiğine Aykırı Eylemler başlığı altında belirtilen eylemlerden hiçbirinin gerçekleştirilmediğini taahhüt ederim.

\section{Çıkar çatışma beyanı}

Conflicts of interest

$\mathrm{Bu}$ çalışmada çıkar çatışması olmadığını beyan ederim.

\section{Kaynaklar \\ References}

Asiedu, Y., \& Gu, P. (1998). Product life cycle cost analysis: state of the art review. International Journal of Production Research, 36(4), 883908. https://doi.org/10.1080/002075498193444.

Balıkoğlu, F., Demircioğlu, T., Yıldız, M., \& Arslan, N. (2016). Oluklu PVC köpük içeren denizel sandviç kompozitlerin darbe test performansları.
Ballkesir Üniversitesi Fen Bilimleri Enstitüsü Dergisi, 18(2), 104-115.

Carpenter, J. A. (2008). Challenges and Opportunities for Automotive Composites, SPE Automotive Composites Conference and Exposition, Troy, MI, USA, CD Rom Proceedings.

Carruth, M. (2011). Design optimization case study: car structures. University of Cambridge, Birleşik Krallık.

Dil, T. (2016). Polimer matrisli kompozitler de sarım açısının mekanik özelliklere etkisi [Yüksek Lisans Tezi, Anadolu Üniversitesi, Fen Bilimleri Enstitüsü].

Doku, M. (2009). Karbon fiber esasl polimerik matrisli kompozitlerin üretimi ve karakterizasyonu [Yüksek Lisans Tezi, İstanbul Teknik Üniversitesi, Fen Bilimleri Enstitüsü].

Fan, H.L., Meng, F.H., \& Yang, W. (2007). Sandwich panels with kagome lattice cores reinforced by carbon fibers. Composite Structures, 81, 533539.

https://doi.org/10.1016/j.compstruct.2006.09.01 1.

Hull, D., \& Clyne, W. (1996). An Introduciton to Composite Materials (2nd ed.) Cambridge University Press.

Ölmez, S. (2018). Otomotiv endüstrisinde kullanılan polimer matrisli kompozit malzemeler [Yüksek Lisans Tezi, Pamukkale Üniversitesi, Fen Bilimleri Enstitüsü].

Öz, S. (2014). Farkl karbon tekstilleriyle ve reçinelerle oluşturulan karbon kompozitlerin karakterizasyonu [Yüksek Lisans Tezi, İstanbul Teknik Üniversitesi, Fen Bilimleri Enstitüsü].

Özarslan, H., Yavuz, H., \& Darıcık, F. (2018). Elektrikli araç uygulamaları için hafif kompozit şase tasarımı ve geliştirilmesi. Çanakkale Üniversitesi Fen ve Mühendislik Bilimleri Dergisi, 36(7), 9-16.

Yılmaz, U., \& Evci, C. (2015). Havacılık ve savunma sektöründe kompozit malzemelerin geleceği. Savunma Bilimleri Dergisi, 14(2), 78-109. 